\title{
HRM during Pandemic and Uncertainty
}

\begin{abstract}
Covid-19 pandemic has caused unprecedented challenges for businesses and people. The state of uncertainty, volatility and ambiguity caused due to fast spreading coronavirus and the consequent havoc and distress inflicted on people's life and business operations, has made people rethink about life, redefine priorities in life, and companies evolving new business models and agile ways of working through digital transformation, to sustain themselves. Pandemic being primarily a "People-based crises" has brought the centrality of HRM in confronting the situation, aligning and driving sustainable change at multiple level, whether individual behaviour, cultural or organizational level. The exploratory qualitative research using "expert interview" methodology has been leveraged to find out the top people-related challenges faced by the organizations, besides discovering the evolution of diverse HRM functions in the new normal and the future directions.
\end{abstract}

Keywords: Pandemic, HRM, Digital HR, HR transformation, Employability, New normal

\section{Introduction}

The outbreak of COVID-19 (or, Coronavirus Disease 2019), which was first reported in the city of Wuhan (China) in December 2019, had fast propelled to the status of a global pandemic, as declared by WHO on March 11, 2020. It has had tremendous impact on societies, economies, organizations and people from all walks of life across the globe, suddenly plunging the world in the grip of fear, uncertainty and ambiguity. All of a sudden, many businesses had to close down, people couldn't travel to and for work, consumer demand dipped, supply chains got disrupted, job losses and pay cuts became rampant, all social activities came to a halt and people started experiencing unprecedented health crisis which local health facilities and infrastructure couldn't handle. While the concept of VUCA (i.e., volatile, uncertain, complex, and ambiguous) environments had been known and studied earlier (Van Tulder, Verbeke, \& Jankowska, 2019), however, this pandemic situation offered one of the extreme manifestations of the VUCA environment, and made both people and businesses sit up and realize its relevance. Already in the $21^{\text {st }}$ century, the world had seen several disrupting events, like natural disasters, global financial crisis, corporate scandals, terrorist activities, but the scale, magnitude and impact caused by Covid-19 pandemic has been most profound and unprecedented.

The businesses around the world were caught by surprise, as there were no tried and tested models and best practices to fall back on. There was no remedy of the disease in sight and nobody knew till when such a crisis will last. Due to the abruptness in turn of the events, the strategies to survive were hard to come by, often unclear and fragmented. A 2019 survey of Ernst \& Young, one of the Big Four Global accounting firms, across 500 board members and Chief Executive Officers (CEOs) globally, rightly found that around $80 \%$ of the respondents did not believe their companies were geared up to handle a large adverse risk (EY, 2020). While some organizations tried to quickly move to the digital space, and started to 
reconfigure their systems and processes to enable remote working, however, in many other organizations, possibility of remote working was itself remote. There were many companies who had not adopted the digital strategy earlier and had no way to continue their operations.

While the concerns and pain-points emerged in almost all facets of the societies and communities, like government functioning, economy, education, employment, supply chain and distribution, infrastructure development, health vulnerabilities, etc, however, all of these concerns centred around people's inability to carry out their professions, occupations, services and day to day work, either due to lockdown, quarantine, illness or death in the family, etc. The crisis seems to have originated, perpetuated and assumed alarming proportions due to human omissions, commissions and unpreparedness. The pandemic also impacted the people's health, well-being and sense of vitality, which led to serious talent concerns for the organizations, besides disruption in employees' lives, occupations and productivity. The situation, alongwith other environmental factors, in turn cascaded the crisis in most facets of economies and businesses. The Boston Consulting Group (BCG) had rightly termed the ongoing COVID-19 pandemic as a "people-based crisis". Just as the Great Financial crisis (GFC) in 2007-2008 had plunged the world economies into doldrums which highlighted the role of talented and responsible Chief Financial Officers (CFOs), the current corona virus caused pandemic has caused an acute people-based crisis, which has brought into limelight the role of Human Resource Management (HRM) and the need for talented and effective Chief Human Resource Officers (CHROs) to steer the organizations out of the current mess. As custodians of organizational culture, "people champions", "organizational change agents", and being primarily responsible for design of work, keeping employees engaged, maintaining their morale, and integrating the health and safety of employees with workplace practices, the HRM professionals were expected to take the lead in times of this crises. As physical working in offices became almost impossible, HRM function had to colead the remote-working experiments, redesign the workflow processes, enhance touch-points with the employees, provide morale and material support to the employees, implement agile workforce strategies, and even support closure of some businesses, or effect lay-offs, paycuts and retrenchment, so as to eventually ensure organization's continuity and sustenance. Just as everybody else, HRM professionals were also treading on uncharted territories and trying to do things hitherto untested. In many cases their roles got completely redefined from the "traditional hiring, firing and giving pay checks to employees". More than ever before, it became important for HRM function to not only reinvent itself but also collaborate strongly with other business functions like IT, Finance, Legal, Facilities and Safety, etc. In many cases, both the content and the scope of responsibilities of HR teams got expanded, while there were other instances where HRM professionals moved into completely new roles. These developments further reinforced the dynamism and multifaceted roots of HRM role in organizations, which even in normal times, is required to integrate multi-disciplinary theories and philosophies with workplace practices in order to make business achieve its objectives and strategies.

\section{Literature Review}

Although pandemic is still not over and it continues to rage in multiple countries with varying intensities, some research studies had already been conducted in the last one year on the concerns, impact and evolving trends due to the pandemic on the people, organizations and HRM.

COVID-19 pandemic has been primarily responsible for a substantial slowdown in the world economic activities (Brodeur et al., 2020; Gourinchas, 2020), increasing "furloughs and layoffs" (World Economic Forum, 2020), that has further led to soaring unemployment rates 
in multiple countries. Other studies pointed out that the pandemic had caused infinite misery as workplaces and institutions had to close down (Ferguson et al., 2006), or the working hours had to be curtailed as measures to mitigate the severity and spread of the disease. Since businesses across the globe couldn't function to their installed capacities for an extended period of time, most of them had no option but to resort to extensive lay-offs and redundancies of their employees, that eventually brought down the level of employment all across and wrecked untold distress and disruptions in all walks of life. The pandemic has virtually conducted a "Stress test" of the competencies of companies and the governments around in the world in handling the vagaries, uncertainties and complexities in the environment.

Covid-19 pandemic has caused tectonic changes around the world which literally has forced the organisations to respond and adapt to the changes in the business environment and somehow endeavour to manage their workforce (Carnevale \& Hatak, 2020). Another study pointed out that since crises was far from over and similar crises situations- man-made or natural, could occur again, so it was necessary that the companies do systemic changes, adopt platform-based technologies and evolve innovative business models to prepare for turbulence ahead (Sheppard, 2020). Carnevale \& Hatak (2020) pointed out that the key role of HRM in supporting the workforce to handle the difficulties caused by the sudden changes in the workplace and in the society. Sheppard (2020) in his study also highlighted the acute need for the workforce to have digital and collaborative skills in order to transition to the virtual work, which had become a necessity all of a sudden. Infact, the pace of digitization and workplace automation has accelerated manifold due to the pandemic, which has brought to the fore new communication technologies to enable employees to work from home (Goldstein, 2020). It was not that the work-from-home was not practiced earlier, but was been allowed selectively as a privilege for a limited time or as per demands of a specific role. But with the outbreak of pandemic, it could no longer be optional. One research study pointed out that around $50 \%$ of the companies had greater than $80 \%$ of the employees working from home during the early phase of the pandemic with some concerns raised over levels of productivity (Gartner, 2020). The concoction of work and private life while working remotely from home, is the source of one of the core challenges being felt during pandemic times (Peasley, Hochstein, Britton, Srivastava, \& Stewart, 2020).

While, tech-enabled companies in the IT, ITES space could migrate with minor hiccups, however, most other non-IT enabled businesses and small-scale industries could not. Another India-specific study done by Gartner indicated that 54\% of the companies in India did not have requisite technology and resources for employees to work to home, because of dilapidated desktops/ laptops, poor network connectivity and inadequate UPS backup, etc. The study also pointed out that more than 2/3rd of employees in such companies lacked access to information such as Microsoft Teams, Zoom, Google Meet, Group Chats, Skype, GoToMeeting, Cisco WebEx, document sharing, and other software used for virtual working. All this had created workplace inequalities, as on one hand, many employees lost their utilities for their employers and got fired, there were other set of employees in same/other industries, who became more valuable than ever and started getting hefty retention, bonuses and other non-financial incentives.

For employees across industry verticals, lack of socialisation and informal connect with fellow colleagues caused more loneliness, isolation and aggravated the mental health issues (Carnevale \& Hatak, 2020). Besides, stress factor on the employees worsened due to skyrocketing expectations of the managers who wanted their team members to work on $24 * 7$ basis. This made it difficult for employees to unplug from work while at home, thus blurring of the boundaries between work and home, disrupting the employee's work-life balance (Chawla et al., 2020), and impacting their productivity. For many employees, their roles got 
merged with others, or got defunct either due to skill issues or due to business viability concerns, but for most employees, their roles changed radically and irreversibly. It was nothing less than a "career shock" for most employees as they had to rethink their career directions and goals all over again after facing short-term setbacks like reduced or delayed salaries, cut in benefits, job losses, etc (Akkermans et al., 2020). The employees had no choice but to learn new skills to enhance their employability and remain a part of the digital revolution (Sheppard, 2020). Even many managers and HR Leaders had not led teams in a completely remote environment earlier and didn't have any clue on how to engage, collaborate and get work done in a virtual environment (Caligiuri et al., 2020). They had to learn on the go and hence the gaps and challenges in managing the company's human resources, were inevitable.

\section{Research Methodology}

The research used exploratory qualitative approach to get primary data for this research through "face-to-face interviews" through Google Meet platform during June and October, 2021. Using convenience sampling technique while leveraging the personal contacts of the researcher, such respondents were identified who were heading the HR function of their organization in India across diverse industries (viz., Information Technology, Business Process Outsourcing, Legal, Telecom, Education), having minimum 10 years total experience and at least 2 years tenure in the current organization. This "expert interview" methodology got regulated by the research questions, and helped the researcher to "discover" instead of "testing variables" (Corbin \& Strauss, 2008). Invites for the interviews were sent to 39 Heads of HR, however, due to the nature of research work, confidentiality of the company information, non-availability or personal issues of certain experts (HR Leaders), the number of respondents got limited to 31, despite multiple follow-ups and reminders. The sample size ultimately achieved was significant, although as per literature review, sample size of 10 could have been regarded as a sufficient sample size to analyze (Glaser \& Strauss, 1967; Baker \& Edwards, 2012).

The interviews that lasted for about 30 minutes each, were semi-structured so as to be sufficiently open to capture the perspectives and reflections of the experienced HRM professionals, yet follow a broad structure in terms of the identified objectives.

The following open-ended research questions were identified for this study:

Q1: What were the top 3 positives and top 3 people-related issues or challenges, that you faced in your organization post the outbreak of Covid-19 pandemic?

Q2: How did the different HRM functions of your organization evolve in the backdrop of pandemic?

Q3: What are the future directions and focus areas of HRM that you plan to work on for the post-pandemic period?

The interview sessions were recorded for analysis purpose, with express permission from each respondent, with a commitment that complete confidentiality and anonymity will be maintained regarding the information shared by them. The qualitative data was coded by identifying themes/sub-themes and their respective frequencies, wherever required, followed by data analysis, interpretation, conclusions and recommendations.

\section{Data Analysis \& Discussions}

The 31 respondents were from diverse industries- (a) Information Technology (IT)- 8; (b) Business Process Outsourcing (BPO)- 7; (c) Telecom-7; (d) Law firms- 4; (e) University-5. Out of total 31 respondents, 20 were males and 11 were females. Average working experience of respondents was 15 years with minimum tenure of 3 years in their current organization. 
Regarding the first research question on positives experienced post the outbreak of Covid-19 pandemic, most respondents were unanimous that the crisis brought to the fore the centrality of the human aspect in management of the organization. Managers and leaders who were themselves experiencing pain and distress in their surrounding naturally became more sensitive to employee needs and expectations, which contributed to humanising the workplace. The other straight benefits that emerged were that business continuity plans started to be taken seriously by organizations, which hitherto remained on paper only. Digital transformation and adoption of alternate modes of employment and engagement, which used to be need and role-based earlier, and often subject to budgetary constraints to be put off to some future times, suddenly got pre-eminence and got agreed for implementation in no time. Regarding the people-related issues or challenges faced post the outbreak of Covid-19 pandemic, the respondents shared diverse issues like Lack of Agility, redefining organizational performance, health and well-being of employees, engaging employees remotely, managing work expectations in a completely virtual environment, balancing employee benefits and job security with business continuity, resetting business and HR practices in uncertain future, ensuring collaboration under stress and grooming/developing leaders during volatility and ambiguity. However, the top 3 issues identified through the research were- (i) Resetting business and HR practices in uncertain future (85\%); (ii) Health and well-being of employees (78\%); (iii) Balancing employee benefits and job security with business continuity $(60 \%)$.

On the $2^{\text {nd }}$ research question, viz. Q2: How did the different HRM functions of your organization evolve in the backdrop of pandemic, multiple open-ended questions were asked pertaining to diverse functions/sub-functions of HRM one by one to elicit the response.

Recruitment \& Onboarding: HRM professionals are leveraging technology to screen, evaluate and engage with potential candidates. Social media platforms like LinkedIn, Facebook and Twitter, coupled with Digital job boards, virtual job fairs and AI-powered recruitment tools, are being used extensively for recruitment purposes. Resume screening through Applicant Tracking system (ATS) and telephonic interviews were already being practiced before pandemic struck. With social distancing becoming a norm and travel restrictions being in place, video interviews and video-conferencing based meetings, including online platforms like Google Meet, Skype and Zoom, have now taken stronger roots and are considered a viable and effective solution to taking objective hiring decisions.

Onboarding and induction of employees has also gone predominantly online. Candidates are sent a link through a few days before their actual date of joining, through which they can enter all details, complete joining formalities, upload documents, verify credentials, get trained and know about different facets of the organization online. In order to keep the candidates and new employees engaged, organizations are increasingly using gamification to combine learning with fun, recognition and camaraderie. HR teams vouch for this scalable model and are building this as a long-term digital recruitment strategy for the post-pandemic world. Virtual Reality is also being experimented by some organizations to give a virtual walk-through of the workplace and give the new employees a real feel of working there. IT teams ensure that all the email IDs, login credentials and other hardware and software resources, especially the communication tools, online meeting solutions and file-sharing applications etc., are made available to new employees on their first day itself and the new joiners home office is set-up. HR team provides access to company policies, processes and resources pages having all the information that the new joiner needs to settle down. Multiple virtual social gatherings are held in in the initial 1-2 weeks so that new joiner is able to socialize virtually and get to know his/her colleagues at personal level. Buddies are also assigned to each new joiner to help them navigate the initial phase without any major issues. 
Performance Management: Once the new employee has been onboarded and inducted in the organization, the short-term/long-term goals, workplans, expectations and job responsibilities are shared by respective manager. A protocol and schedule for daily, routine catch-up calls in teams setting and frequent 1:1 check-in call, is also set up. These calls help to calibrate, discuss forthcoming tasks, share feedback, resolve any potential concerns and align team members with a common vision.

Wherever required, dedicated problem-solving and coaching sessions are held with the concerned employees at short notice, so that employees get timely support and clarification that they need to reinforce their productivity and help them achieve their defined goals and objectives.

Employee engagement: In addition to above practices, organizations hold frequent pulse meetings or surveys, or "temperature checks", or "Mood-o-meters" to know what is going on in the minds of their people at different points of time. Many times, it results in disbanding or streamlining old HRM practices, or sensitizing managers, or issuing clarifications to clear the air, or rejig the current system. By being sensitive to employee feedback and concerns and demonstrating timely improvements, organizations demonstrate that employee's opinion matters, enhances their ownership in the assigned tasks and motivate them to stay longer. Also, work and jobs get redesigned regularly to give more control to employees and teams over their work, with managers acting as facilitators and sounding boards in bouncing off ideas and brainstorming to arrive at the best solution. In the online environment, managers are being sensitized that overt and frequent display of gratitude, praise and sharing positive feedback on the efforts of employees is very critical to success, employee engagement \& retention. Pandemic has made organizations realize the importance of several non-workrelated factors, like employee's health, child care, house maintenance, family distress, etc, which play in the minds of employees at work and impact their motivation and productivity.

Employee Health \& well-being: Organizations are taking steps to ensure employees remains happy, healthy, resilient and their health-related concerns are proactively addressed, so as to facilitate their physical, social and psychological well-being during the tenure with the organization. Certain new practices adopted by the organizations include online yoga sessions, providing Covid Insurance cover, organising camps within office premises or having tie-up with local hospitals to vaccinate employees, Additional mandatory day-offs, shortened meetings, scheduled "No meeting hour / working day" and "No meeting Friday", flexibility in working hours, launching wellbeing programs focusing on mental and spiritual well-being of our employees and their families, reinforcing Employee Assistance Programs (EAPs), etc.

Compensation and Benefits: This has been one of the biggest casualties during pandemic times, with job losses, pay cuts, suspended bonuses and salary increments, benefits and perquisites being cut down to optimize cost. Almost $50 \%$ of the organizations surveyed had deferred $20-30 \%$ of the employee salaries for 6 months, while the remaining ones had maintained the regular salaries, bonuses and incentives during 2020 and were rethinking strategies in 2021, with focus to manage short-term cost and balance it with long-term resilience in the organization. One of the options being considered was to offer skill-based pay to employees, wherein employers could differentiate pay using incentives that are variable, time-bound, linked to achievement of higher levels of productivity, and could be easily withdrawn when its utility was not felt. Some employers have quite magnanimously started paying last drawn salary to families of employees who died due to Covid-19 for 2-5 years or even till retirement, and/or undertaking to reimburse their children education till the graduation level, and/or providing jobs/upskilling to family members of covid-19 victims among their employees. One clear emerging trend is that the focus is gradually shifting to "beyond pay", as employees have started to value workplace flexibility, job security, work- 
life balance more than ever. Many employees seem unwilling to travel and instead prefer to work from their homes at far-off locations albeit with lower salaries and benefits.

Learning \& development: Covid-19 has perpetuated mismatch between supply and demand of qualified workers on the labour market. Organisations have realised it now more than ever that competencies required for business success are centred around people, whether through innovation, business development, customer service, knowledge management, leadership during crisis, culture development and employee competence development practices, etc. Upskilling and reskilling current employees are helping organizations sustain themselves while optimising cost. As business models have been disrupted, product life cycles have shortened and turnaround times have reduced drastically, therefore learning is getting integrated into employee's every day work, as off-the-job classroom trainings are getting deprioritized. As work and roles are getting redefined post pandemic, focus is less on the rolebased trainings, which generally tend to provide diverse un-related skills, to development of specific critical skills required to achieve competitive advantage and design the workflows around those skills. Organizations are incentivising skill-based learning, laying more focus on self-learning by employees, followed by teach-backs and supported by creation of learning communities, thus encouraging social learning where team members acquire new behaviours by observing or imitating others. This approach is not only helping employees to learn faster but also enhances their engagement levels. Virtual collaboration rooms and mentoring networks are being used for grooming potential leaders. Managers are also being trained on how to effectively lead remote teams, building personal resilience, deal with ambiguities, manage performance, give feedback, and being provided coaching skills to develop competencies and potential of their people.

Work arrangements: This pandemic has seen an abrupt transition from physical working environment interspersed with work-from-home on need basis, to a completely virtual environment due to extended lockdown imposed by the state authorities to prevent the spread of the coronavirus. As the situation eased in between and in the last 2 months, the organizations are either continuing with the same virtual arrangements or are transforming into hybrid workplace for the long-term.

On the $3^{\text {rd }}$ research questions, as to the future directions and focus areas of HRM that they plan to work on for the post-pandemic period, it came out very evidently that Hybrid workplace is here to stay. Reverting back to a completely physical working environment as prevalent during January 2020, is no longer an option on the table. Digital transformation of the organizations is already at an advance stage and it is not practical to undo the gains achieved till now due to it. One of the practices followed by organizations in the last 1.5 years was preference to leased and contingent workforce to handle fluctuations in volume and demand, instead of offering permanent employment, unless the hiring is for futuristic skills which they need to build in the organization. This is likely to continue in the post-pandemic era as well.

Organizations are trying to figure out the right balance between extent of virtual working feasible and organizational effectiveness coupled with individual health and well-being. Organizations are also experiencing greater receptivity from employees to work from home, even with reduced benefits and compensation, since it helps them to cut down on their travel time, expenses, morning rush, traffic-related stress coupled with air and noise pollution outside. They can have more family-time and plan their things better, thus giving them more control of their lives. Besides, for many environmental- friendly employees, it is a chance to reduce the carbon footprint and prevent further environmental degradation, which could have led to the current crisis situation. 


\section{Conclusion and Recommendations}

The pandemic has not only caused a paradigm change from where we work, but is also altering the work we do, who can do it and how it will get done. For this, organizations have to revisit their definitions of talent and value chain analysis which formed the basis of their business model till now.

The COVID-19 pandemic has brought health and safety concerns in the forefront and has brought to limelight the critical role of the HRM function in managing the health and safety of the employees. Undoubtedly, the pandemic-driven virtual working environment has led to longer work hours, greater physical and financial stress, increased work-life conflicts, besides experiencing loneliness, frustration, stigma, boredom and other mental-health issues. These are real concerns and organizations in their spree to go virtual or adopt hybrid work arrangements, should proactively address them and "humanize the workplace" more. It might mean having more non-work virtual meetings, fun activities to re-energize online relationships and maintain the motivation and productivity of employees. To break pandemicimposed silos at home, virtual collaboration has to be encouraged big way, by building and rewarding employees' virtual collaboration skills, facilitating "perceived proximity", and design the workflow and goals accordingly. Organizations have to make sure that work fits into their employees' lives rather than expecting employee to turn their lives topsy-turvy just to fit to the work requirement. The psychological contract with the employees is required to be re-negotiated along with re-organization of the work.

State of uncertainty alongwith unforeseen risks and challenges, have not only impacted the organizational outcomes, but had a telling impact on the individual employee's well-being and engagement levels on multiple fronts. Part of it happened because of lack of prompt, empathetic, transparent and continuous communication between organizations and its employees. This is really one of the most significant pre-requisites for any change management to become successful, which requires attention from the organizations.

During challenging times of pandemic, focus of HRM professionals has to be more on interpersonal relationships rather than rules, standards, control and hierarchy. HR Leaders have to inspire trust by demonstrating competence, respecting diversity, taking credible actions with agility, standing up for issues when it matters, expressing gratitude and appreciation, providing clear directions to others even under ambiguous situations, and always taking their people along in evolving solutions. List of competencies to lead into the future, and also required to the developed in the budding talent, now certainly include cultural agility, tolerance for ambiguity, managing uncertainty, being resilient, remaining curious, collaborating even under stress, and respecting diversity.

As the economy is gradually coming out of the shadows of pandemics, organizations have started to hire more part-time employees and contractors, with flexible work arrangements and job sharing on the rise. Companies are re-evaluating whom they would like to like to retain, retrain or let go, based on the critical skills and demand and supply situation. This calls for reviewing and revamping organization's HR practices, especially the compensation and benefits programs. To make up for the lack of apparent monitoring and control of employee's day to day activities while working from home, organizations have to be techenabled so that with the help of "online dashboards" and digital data, managers could evaluate team member's workload and performance.

HR practitioners need to redesign learning strategies to facilitate employees to gain contemporary skills and technologies and update their digital skills. Instead of taking pride in reducing organizational cost by asking people to go, they have to pride themselves in playing 
a facilitating role in organizational transformation through upgrading their skills and abilities to make them future-ready. Covid-19 has already heightened employees' desire to learn and enhance their employability, which explains resurgence in self-directed learning by employees, that needs to be further reinforced by organizations by offering access to online learning resources, or reimburse employees' online training to achieve synergy between individual aspirations and organizational needs. Future of learning and development lies in adopting "Agile learning methodologies" by the organizations that focus on speed, flexibility and collaboration.

\section{References}

van Tulder, R., Jankowska, B., \& Verbeke, A. (2019). Introduction: progress in international business research in an increasingly VUCA world. In International Business in a VUCA World: The Changing Role of States and Firms. Emerald Publishing Limited.

Brodeur, A., Gray, D., Islam, A., \& Bhuiyan, S. (2020). A literature review of the economics of COVID-19. Journal of Economic Surveys.

Gourinchas, P. O. (2020). Flattening the pandemic and recession curves. Mitigating the COVID Economic Crisis: Act Fast and Do Whatever, 31, 57-62.

World Economic Forum. (2020). The Future of Jobs Report 2020. Geneva: World Economic Forum.

Ferguson, N. M., Cummings, D. A., Fraser, C., Cajka, J. C., Cooley, P. C., \& Burke, D. S. (2006). Strategies for mitigating an influenza pandemic. Nature, 442(7101), 448-452.

Carnevale, J. B., \& Hatak, I. (2020). Employee adjustment and well-being in the era of COVID-19: Implications for human resource management. Journal of Business Research, 116, 183-187.

Sheppard, B. (2020, May 18). A guide to thriving in the post-COVID-19 workplace. Retrieved July 25, 2021, from World Economic Forum: https://www.weforum.org/agenda/2020/05/workers-thrive-covid-19-skills/

Goldstein, J. (2020, June 4). An architecture of optimism in a post-pandemic society. https://vimeo.com/426321673

Gartner. 2020. Gartner HR Survey Reveals $41 \%$ of Employees Likely to Work Remotely at Least Some of the Time Post Coronavirus Pandemic. https://www.gartner.com/en/newsroom/press-releases/2020-04-14-gartner-hr-survey-reveals41--of-employees-likely-to-. Accessed July 202021.

Peasley, M. C., Hochstein, B., Britton, B. P., Srivastava, R. V., \& Stewart, G. T. (2020). Can't leave it at home? The effects of personal stress on burnout and salesperson performance. Journal of Business Research, 117, 58-70.

Trougakos, J. P., Chawla, N., \& McCarthy, J. M. (2020). Working in a pandemic: Exploring the impact of COVID-19 health anxiety on work, family, and health outcomes. Journal of Applied Psychology.

Caligiuri, P., De Cieri, H., Minbaeva, D., Verbeke, A., \& Zimmermann, A. (2020). International HRM insights for navigating the COVID-19 pandemic: Implications for future research and practice. 
Akkermans, J., Richardson, J., \& Kraimer, M. L. (2020). The Covid-19 crisis as a career shock: Implications for careers and vocational behavior.

Corbin, J., \& Strauss, A. (2008). Strategies for qualitative data analysis. Basics of Qualitative Research. Techniques and procedures for developing grounded theory, 3.

Baker, S. E., \& Edwards, R. (2012). How many qualitative interviews is enough. NCRMUniversity of Southampton 